\title{
Ensuring the quality of the machined holes during the hole truing and reaming on lathe machines
}

\author{
Aziz Aliev ${ }^{1, *}$ \\ ${ }^{1}$ Crimean Engineering and Pedagogical University, Uchebniy side st.8, 295055 Simferopol, Russian \\ Federation
}

\begin{abstract}
The article is devoted to studying of the influence of cutting liquids, including those of plant origin, on the roughness of the treated surface during the reaming and deployment in details of titanium alloy, structural and corrosion-resistant steels. The relationships between the characteristics of the adhesive interaction of the tool and the processed materials and the length of the contact area of the tool with the workpiece and heat in the cutting zone are determined. The effectiveness of plantorigin cutting liquids is shown in comparison with conventional oils under conditions of the pronounced adhesive wear.
\end{abstract}

\section{Problem statement}

Depending on the treatment conditions, cutting liquids ensure lubricating, cooling, dispersing, and detergent effects.

Studies aimed at finding ways of the most rational use of lubricating plant oils in machining are very common nowadays [1-3]. Results of closed-cup adhesion tests in ecologically-compliant plant oils with low closed-cup flash point $\left(230 \ldots 240^{\circ} \mathrm{C}\right)$ provided grounds to find these oils effective during operations carried out under processing limits in low cutting modes, and under conditions of pronounced adhesive wear and built up edge formation [4-6].

During hole truing and reaming, the temperature is not high enough to cause diffusive wear, while deformations grow dramatically high. Under such conditions, adhesive wear starts prevailing, leading to built up edge formation. Regularly formed and torn off the contact area, such built up edges may negatively impact the treated surface [7-11].

The influence of processing environment on wear of reamers and core drills provides limited possibilities for analysis due to high efficient life of these tools. During reaming and truing under processing conditions, the treated surface roughness may serve as a cutting liquid quality criterion. In order to prove the suggestions to consider a tool and a raw part as a tribological pair $[12,13]$, we have carried out a set of pilot tests aimed at determining the influence of machining conditions on the height of the treated surface microroughness during reaming and truing.

\footnotetext{
* Corresponding author: alievaziz2704@gmail.com
} 


\section{Materials and methods of research}

The experiments were carried out on SAMAT 400M fine-accuracy screw-cutting lathe when machining 34-mm plugs made of engineering steel 20 (Russian grade), titanium alloy BT1-0 (Russian grade) and corrosion-resistant steel 12X18H10T (Russian grade) [14]. Three types of tests, performed during truing, were as follows: a dry test (no cutting liquids used) and tests using rape oil and Garia 404 M10 (Shell) oil-base cutting liquid fed by spraying under $232-\mathrm{kPa}$ pressure by means of STEIDLE feeding device ensuring light lubrication technique. The environment type constraint was due to the interest in determining the impact of the truing speed on surface roughness.

Reaming was performed with machine reamers made of P6M5K5 steel (Russian grade) in the modes recommended for the above-mentioned materials treating $(v=2,7 \mathrm{~m} / \mathrm{min}$, $S=0,2 \mathrm{~mm} /$ round, $t=0,05 \mathrm{~mm}$ ). As the thickness of the cut layer becomes comparable with the bending radius of the cutting point during reaming, and adhesion-related effects become more pronounced, a wider range of processing environments were studied. Beside rape oil, sunflower oil was also studied, as previous tribological tests had shown its efficiency [15]. The MP-17M cutting liquid (Russian grade), recommended for reaming, was enhanced by И-20 mineral oil (Russian grade), a cutting liquid base [16].

\section{Statement of the main material}

Figure 1 shows experimental relationships between the treated surface roughness and the steel 20 truing speed.

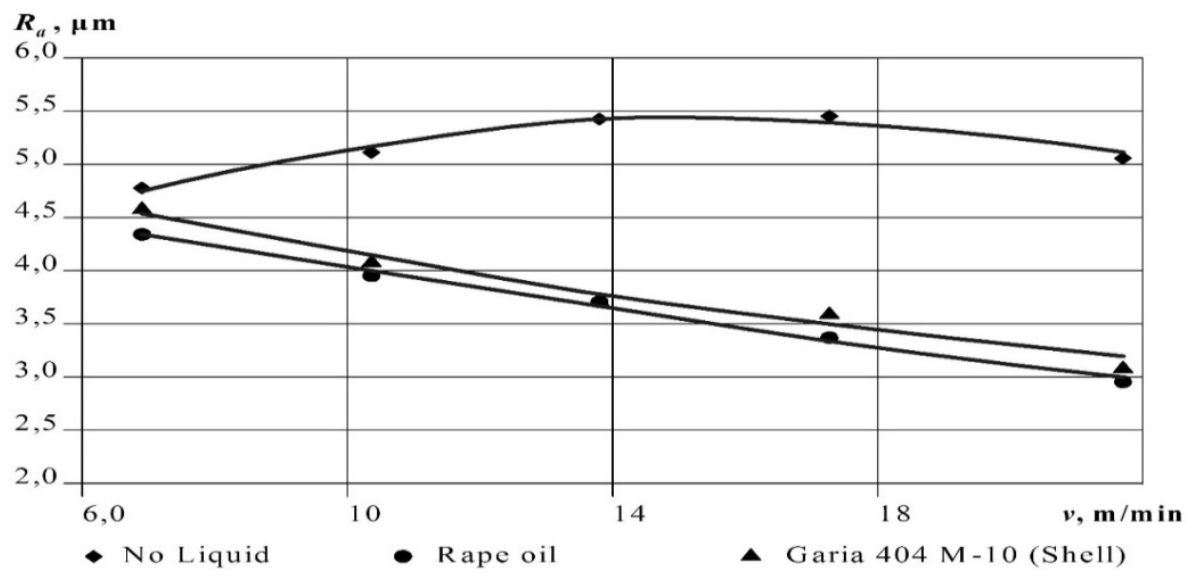

Fig. 1. Cutting liquid impact on surface quality during truing: (P6M5; $\mathrm{t}=0.5 \mathrm{~mm}$; steel 20).

The relationship chart analysis shows that the highest surface roughness occurred at the cutting speed of $17.3 \mathrm{~m} / \mathrm{min}$. During dry cutting at $10-18 \mathrm{~m} / \mathrm{min}$, built up edges are formed, which lead to deterioration of the surface quality. However, with the cutting speed increase, the built up edge formation slows down, while the roughness also decreases. Besides, at high cutting speeds (over $18 \mathrm{~m} / \mathrm{min}$ ), the depth of the plastically-deformed layer decreases, which also improves the surface quality. The use of rape oil and oil-base cutting liquid Garia 404 M10 (Shell) enabled to significantly improve the surface quality. Further acceleration up to $22 \mathrm{~m} / \mathrm{min}$ reduced the arithmetic-mean deviation of the profile $R_{a}$.

Figure 2 demonstrates the experimental data obtained during machining the $12 \mathrm{X} 18 \mathrm{H} 10 \mathrm{~T}$ corrosion-resistant steel. This relationship may enable to determine the range 
of speeds which the surface quality improves at. This way, at speeds between 5.5 and 13.8 $\mathrm{m} / \mathrm{min}$, the microroughness height decreases, and at speeds higher than $13.8 \mathrm{~m} / \mathrm{min}$, the microroughness height rises.

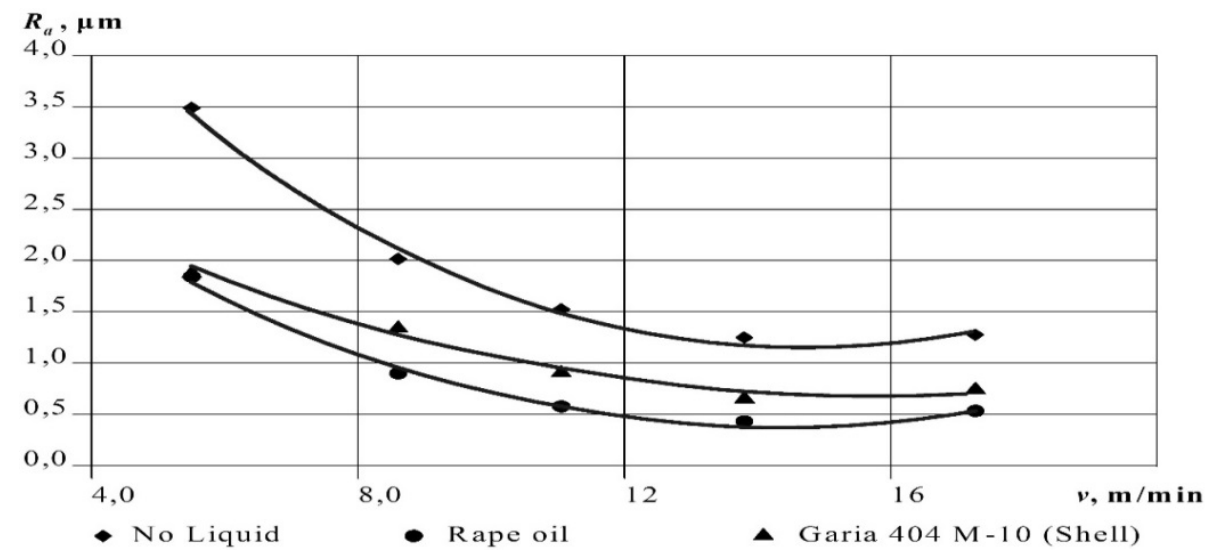

Fig. 2. Cutting liquid impact on surface quality during truing: (P6M5; $t=0,5 \mathrm{~mm}$; steel 12X18H10T).

This is due to the fact that low thermal conductivity of stainless steels causes local overheats, as the heat produced during tool operation is poorly exhausted through the metal mass.

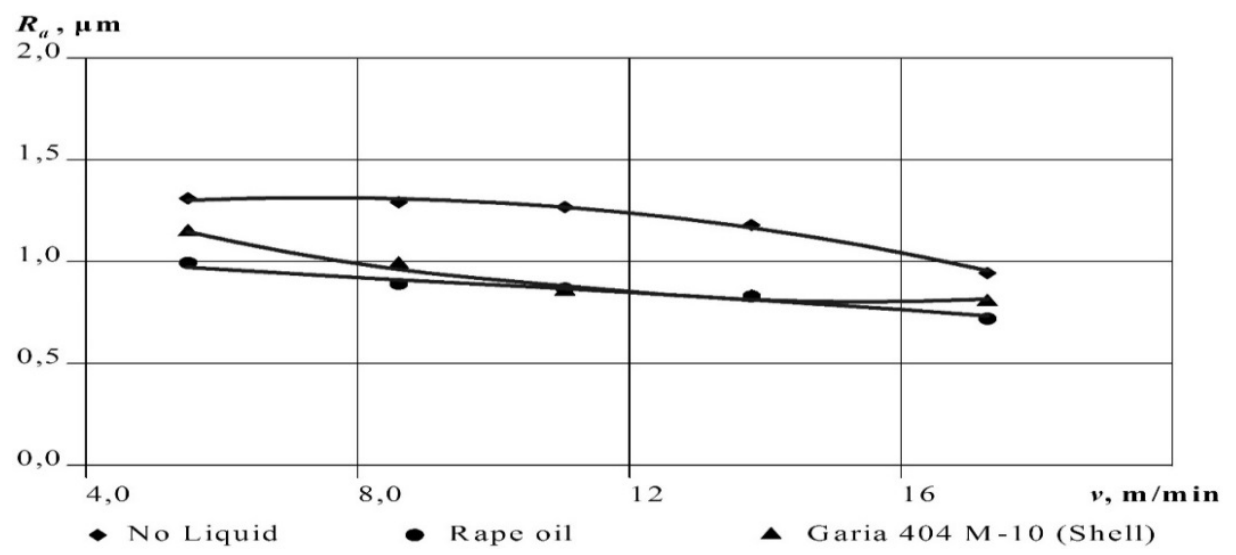

Fig. 3. Cutting liquid impact on surface quality during truing: (P6M5; $\mathrm{t}=0.5 \mathrm{~mm}$; titanium alloy BT1-0).

When feeding the cooling liquid at high speeds, the liquid does not reach the contact area due to high temperatures leading to burnout, thus worsening pitfalls related to local overheats.

During truing plugs made of BT1-0 titanium alloy, the surface quality decreases linearly (Figure 3). The highest roughness value was obtained at the cutting speed of $5.5 \mathrm{~m} / \mathrm{min}$. Cutting with the cutting liquid did not transform the nature of charts, but the trend toward decrease of $R_{a}$ at all cutting speeds was noted.

Table 1 shows that during reaming in raw parts made of corrosion-resistant steel, the studied liquids significantly decreased the roughness parameter $R_{a}$ against dry cutting. Rape and sunflower oils excelled, though not too greatly, both И-20 mineral oil and MP17$\mathrm{M}$ industrial oil-base cutting liquid. It can also be noted that the removal of the reamer bit from the hole machined in the sunflower-oil environment was easy; while in other environments the removal process required some effort. 
Plant oils dramatically decrease the surface roughness [17]. Reaming in titanium-alloy plugs showed deterioration of the surface quality in the environment of И-20 mineral oil against dry cutting, which is indicative of enhancement of adhesion processes noted in previous adhesion tests $[18,19]$. Papers $[19,20]$ made a point that for titanium as a reactive metal, the impact of the environmental gases on adhesion and wear may be more significant than for other metals. Mineral oils highly constrain the invasion of oxygen and nitrogen into the contact area, thus preventing the titanium surface layers hardening and intensifying adhesive wear.

Table 1. Plug reaming roughness parameter $R_{a}$.

\begin{tabular}{|l|c|c|c|c|c|}
\hline \multirow{2}{*}{ Machined material } & \multicolumn{5}{|c|}{ Processing environment } \\
\cline { 2 - 6 } & No liquid & Mineral oil И-20 & MP-17M & Rape oil & Sunflower oil \\
\hline $\begin{array}{l}\text { Corrosion-resistant } \\
\text { steel 12X18H10T }\end{array}$ & 1,358 & 0,409 & 0,327 & 0,297 & 0,288 \\
\hline $\begin{array}{l}\text { Titanium alloy } \\
\text { BT1-0 }\end{array}$ & 0,8 & 0,847 & 0,747 & 0,656 & 0,573 \\
\hline
\end{tabular}

\section{Conclusion}

The studies carried out provide for the following conclusions:

- Light lubrication technique, which significantly reduces lubricant consumption, does not deteriorate the effectiveness of plant oils and ensures the required surface quality;

- The impact of plant oils on contact and deformation processes during truing, pronounced through the decrease of the surface roughness (up to $40 \%$ ), is mostly noticeable during machining of engineering and corrosion-resistant steels. With that, the oil effectiveness correlates with the results of adhesion tests, which reflects opportunities for plant-oil lubricating effect when reaching the contact area at low cutting modes;

- During titanium alloys machining, high contact loads deteriorate conditions for oil (and plant oil) invasion, and adhesion-related effects are not pronounced;

- The relationships between the surface roughness and the cutting speed and type of the used cutting liquid, obtained during the tests, showed that the plug surface roughness decreases with the speed-up of cutting; except for dry machining of steel 20, when built up edges are formed at speeds $10-18 \mathrm{~m} / \mathrm{min}$. Higher activity of liquids leads to lower roughness;

- Enhancement of adhesion processes, noted during adhesion of the contact pair P6M5K5 - BT1-0 in mineral oil, is pronounced during reaming; this leads to deterioration of the surface quality against no-environment cutting;

- Use of plant oils as processing environments for operations of high adhesion wear (truing, reaming) is indicative of their competitive performance against not only mineral oils, but also traditional oil-base cutting liquids.

\section{References}

1. H.-G. Schmidt, Komplexester aus pflanzlichen Ölen - pp.2.2-1-2.2-9 (9th International Colloquium; Vol II, Esslingen, 1994)

2. N.P. Mazur, Yu.N. Vnukov, V.L. Dobroskok, V.A. Zaloga, Yu.K. Novoselov, F.Ya. Yakubov, Fundamentals of the theory of cutting materials, (Lviv, 2010)

3. Ch. Yakubov, R. Dzhemalyadinov, The impact of technological liquids on the power features and quality of processed surface drilling in various construction materials, 
Scientific notes of the Crimean engineering and pedagogical University. Vol. №1(51) Technical Sciences. pp.132-137, (2016)

4. A.I. Aliev, Ch.F. Yakubov, Effect of oils of plant origin on adhesion processes at various temperatures, Cutting \& Tool in Technological System, vol. 61, pp.3-5 (2002)

5. A.I. Aliev, Scientific notes of the Crimean engineering and pedagogical University. Vol. 27, Technical Sciences, pp.42-46, (2011)

6. S. Debnath, M.M. Reddy, Environmental friendly cutting fluids and cooling techniques in machining (Q.S.Yi. - Prod. 2014. - 83 p.)

7. G.S. Gheleznov, S.G. Andreyeva, Securing required surface undulation of machined surface by reaming, Vestnik Mashinostroeniya, №6, pp. 67-69, (2013)

8. A.V. Shashok, A.V. Kutyshkin, E.A. Frolov, I.V. Kogemyko, Prediction of adhesive flank wear of the cutting tool, Obrabotka metallov: metal working and material science, №1(50), pp. 23-26, (2011)

9. A.S. Yamnikov, Nguyen Wang Kyong, O.A. Yamnikova, Influence of giving and geometry of the cutting edge on the settlement roughness the processed surface, Izvestiya TulGU, Vol. 11, part 1, pp.67-73, (2014)

10. P.A. Linchevsky, V.D. Iorgachev, L.B. Shron, V.B. Bogutsky, B.L. Shron, Features of combined processing of the main holes in power units of agricultural machinery. Scientific works of the South branch of the National University of Bioresources and Nature Management of Ukraine "Crimean Agrotechnological University". Series: Engineering. №.146, pp. 136-142, (2012)

11. L.B. Shron, V.B. Bogutsky, F.N. Canareev Use of methods of photomechanics for the analysis of threading processes. Bulletin of modern technologies. №.2(2), pp.81-85, (2016)

12. V.T. Protsishin, O.A. Mishchuk, M.A. Nyrkov, A.V. Bogaychuk, A.N. Ermakov, A.I. Aliev, Tribological Behaviour of Lubrication-Cooling Technological Surroundings and the Procedure of Their Measurement, Equipment and Tools for Professionals, №1. - pp. 54-58, (2007)

13. E.R. Vaniev, Herald SSU, http://essuir.sumdu.edu.ua/handle/123456789/9411, (2010)

14. S.I. Pestretsov, A.A. Rodina, Mathematical Modeling of Reaming and Optimization of Geometrical Parameters of Cutting Tools in SolidWorks Premium 2012 Environment V.I. Vernadsky University, №3(41), (2012)

15. A.I. Aliev, F.Ya. Yakubov, A.S. Vavulitskiy, Modern Technologies of Engineering, v. 1, pp. 17-22, (2007)

16. E.D. Berliner, I.A. Buyanovskiy, The monthly scientific and industrial journal FRICTION \& LUBRICATION IN MACHINES AND MECHANISMS, №6 (2012)

17. E.Sh. Dzhemilov, M.L. Shabdinov, The research of the contact interaction of the tool with a part in the deployment of holes, Vestnik SevNTU, Vol. 139, pp.69-75, (2013)

18. A.I. Aliev, Herald SSU, http://essuir.sumdu.edu.ua/handle/123456789/11015, (2005)

19. M.Yu. Smolyakova, D.S. Vershinin, Study of Tribological Characteristics of Layers Modified with Nitrogen Ions on VT16 Titanium Alloy, Transactions TSTU, Vol 18, № 4, (2012)

20. V.A. Krivouhov, D.M. Chubarov, Cutting of titanium alloys, M. Machinebuilding, (1970)

21. E.A. Marchenko, S.M. Kaplunov, Yu.V. Korovkin, D.G. Efros, V.A. Panov, Tribological properties of some titanium alloys for heat exchange equipment, The monthly scientific and industrial journal FRICTION \& LUBRICATION IN MACHINES AND MECHANISMS, №10, pp. 30-34, (2010) 